\begin{tabular}{|l|}
\hline Learning points \\
\hline $\begin{array}{l}\text { Nail-patella syndrome is a rare autosomal } \\
\text { dominant disorder with characteristic skeletal and } \\
\text { renal abnormalities, most commonly dysplastic } \\
\text { nails, hypoplastic/absent patellae, and } \\
\text { asymptomatic urinary abnormalities }\end{array}$ \\
\hline
\end{tabular}

Box 3

1 Bennett WM. Nail-patella syndrome. In: Jacobson HR Striker GE, Klahr S, eds. The principles and practice of nephrology. St Louis: Mosby, 1995; pp 259-60.

2 Campeau E, Watkins D, Rouleau GA, et al. Linkage analysis of the nail-patella syndrome. Am f Hum Genet 1995; 56: 243-7.

3 Bennett WM, Musgrave JE, Campbell RA, et al. The nephropathy of the nail-patella syndrome: clinicopathologic analysis of 11 kindred. Am $\mathcal{F}$ Med 1973; 54: $304-19$.

\section{Final diagnosis}

Nail - patella syndrome or hereditary onychoosteodysplasia.

\section{Question}

What is the most probable diagnosis?
Department of Surgery, East Surrey Hospital, Redhill, Surrey RH1 5RH, UK

F Calder

H Souka

R Lightwood

Correspondence to Dr F Calder,

Department of Surgery, St Thomas' Hospital, Lambeth Palace Road, London SE1 7EH, UK

Accepted 17 July 1996

\title{
An unusual late complication of gastric surgery
}

\author{
F Calder, H Souka, R Lightwood
}

A 52-year-old man presented with a history of colicky epigastric pain, intermittent upper abdominal distention and diarrhoea worsening over a period of six months. Over 20 years previously a vagotomy and pyloroplasty had been performed for a chronic duodenal ulcer after which he complained of similar symptoms to the above. These were attributed to dumping syndrome, and settled with simple dietary advice at that time.

Initial investigation involved full blood count, urea and electrolytes (which were normal) and a barium meal examination (figure 1).

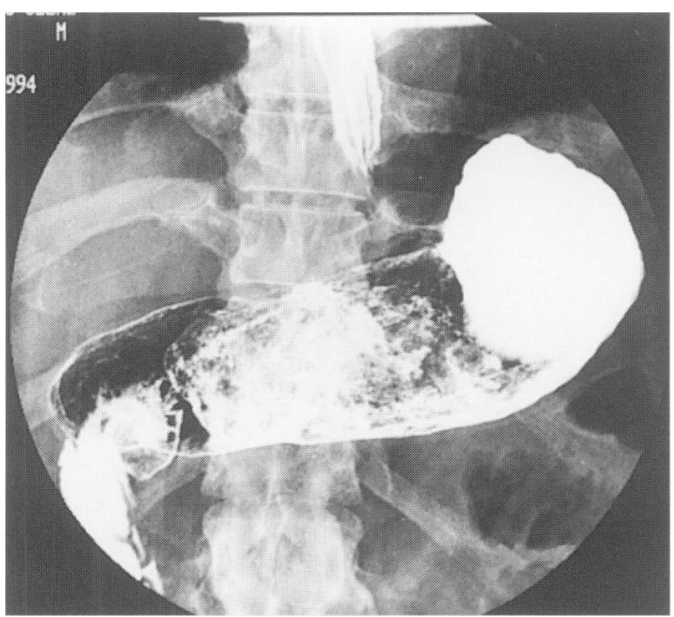

Figure 1 


\section{Answer}

A bezoar. The barium meal examination was reported as demonstrating significant gastric stasis with considerable food residue and outflow obstruction. This was followed by gastroscopy which revealed a large solid mass conforming to the contours of the stomach which was removed by gastrotomy (figure 2)

\section{Discussion}

Bezoar formation is an oft-forgotten condition causing symptoms of upper gastrointestinal disturbance in patients who have undergone gastric surgery. Epigastric pain, weight loss,

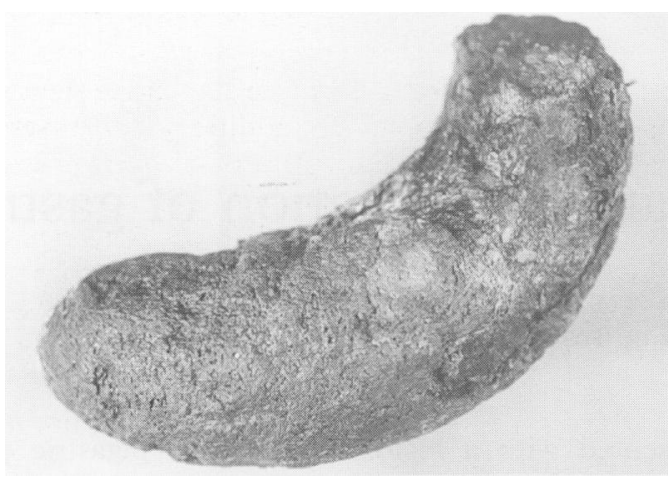

Figure 2 Phytobezoar forming cast of the stomach

1 Diettrich NA, Gau FC. Postgastrectomy phytobezoars endoscopic diagnosis and treatment. Arch Surg 1985; 120: $432-5$

2 Gulsrud PO, Taylor IL, Watts HD, Cohen MB, Elashoff J Meyer JH. How gastric emptying of carbohydrate effects glucose tolerance and symptoms after truncal vagotomy with pyloroplasty. Gastroenterology 1980; 78: 1463-71. nausea and bloating ${ }^{1}$ are the commonest presenting features, strikingly similar to those associated with dumping syndrome. The rapid liquid emptying and slowed solid transport seen after vagotomy and pyloroplasty ${ }^{2}$ contribute significantly to the pathophysiology of both conditions. Other factors such as diet (especially persimmons and oranges), impaired gastric motility, decreased luminal acidity ${ }^{3}$ and poor chewing ${ }^{4}$ are also associated with bezoar formation. Endoscopy is the investigation of choice, since upper gastrointestical barium studies often fail to demonstrate bezoars. ${ }^{1}$

Treatment options include endoscopic fragmentation $^{1}$ intragastric enzymic dissolution, ${ }^{5}$ and gastrotomy.

\section{Final diagnosis}

Gastric bezoar

Keywords: gastrectomy complication, bezoar

\section{Summary/learning points}

- previous gastric surgery predisposes to gastric bezoar formation

- epigastric pain, weight loss and bloating sensations are the common presenting symptoms

- endoscopy is the investigation of choice

3 Sanderson I, Ibberson O, Fish EB. Gastric phytobezoar following gastrectomy. Can Med Assoc F 1971; 104: 1115 - 9. 4 Stien DT, Ballin R, Stone BG. Endoscopic removal of gastric phytobezoars. f Clin Gastroenterol 1982; 4: 329-32. 5 Zarling EJ, Moeller DD. Bezoar therapy: complication using Adolph's meat tenderizer and alternatives from literature review. Arch Intern Med 1981; 141: 1669-70. 